\title{
Keanekaragaman Aves di Kawasan Cagar Alam Pananjung Pangandaran
}

\author{
Iwan Setia Kurniawan ${ }^{1,2 *}$, Fransisca Sudargo Tapilouw ${ }^{1,3}$, Topik Hidayat ${ }^{1,3}$ dan Wawan \\ Setiawan ${ }^{1,4}$ \\ ${ }^{1}$ Sekolah Pascasarjana, Universitas Pendidikan Indonesia \\ 2Departemen Pendidikan Biologi, Universitas Pasundan \\ ${ }^{3}$ Departemen Pendidikan Biologi, Universitas Pendidikan Indonesia \\ ${ }^{4}$ Departemen Pendidikan IImu Komputer, Universitas Pendidikan Indonesia \\ *E-mail: iwansetiakurniawan@unpas.ac.id
}

\begin{abstract}
Abstrak
Aves memiliki potensi yang menarik untuk diamati dengan berbagai jenisnya. Penurunan populasi aves banyak disebabkan karena perburuan liar untuk keperluan komersil. Penelitian ini bertujuan untuk mengidentifikasi aves di kawasan Cagar Alam Pananjung kabupaten Pangandaran. Metode yang digunakan deskriptif dengan desain penelitian menggunakan desain point count pada 10 stasiun (titik pengamatan). Hasil penelitian menunjukan terdapat 43 jenis aves yang berhasil diamati pada seluruh stasiun dari 26 famili. Terdapat beberapa jenis aves yang termasuk dalam kategori terancam punah dan rentan. Hasil analisis setiap stasiun dapat disimpulkan bahwa beberapa jenis aves banyak ditemukan dikawasan hutan dengan vegetasi pohon-pohon tinggi hal ini dikarenakan mereka lebih aman untuk berkembang biak dan bertahan hidup daripada didekat pemukiman atau kawasan wisata. Perlu adanya tindak lanjut dari pemerintah setempat untuk upaya konservasi yang lebih serius dimasa yang akan datang agar supaya dapat mencegah penurunan populasi yang signifikan.
\end{abstract}

Kata kunci: identifikasi, aves, cagar alam pananjung

\section{PENDAHULUAN}

Keanekaragaman jenis burung di Indonesia sering kali dikaitkan dengan kondisi lingkungan, semakin tinggi keanekaragaman jenis burung maka semakin seimbang suatu ekosistem di wilayah tempat hidup burung (Endah \& Partasasmita, 2015). Burung adalah spesies yang menarik untuk dikaji dengan berbagai karakteristik. Penelitian tentang burung saat ini diperlukan, karena telah terjadi penurunan dalam beberapa spesies burung karena perburuan. Dengan demikian, penurunan populasi burung secara tidak langsung mempengaruhi keseimbangan ekologi dan konservasi, sehingga diperlukan pelestarian (Kurniawan, et al. 2017). Burung merupakan satwa yang mempunyai mobilitas tinggi dan memiliki kemampuan penyebaran yang luas pada area terbuka, banyak hidup dikawasan hutan, pedesaan, perkotaan bahkan dikawasan pada penduduk (Saefullah, et al. 2015, Reifani, et al. 2019). Burung sanngat berperan dalam ekosistem, perubahan struktur dan komposisi vegetasi akan berpengaruh pada keanekaragaman spesies burung. Keanekaragaman burung pada suatu daerah dapat dijadikan indikator untuk kestabilan daerah itu sendiri (Ayat \& Tata, 2015; Susanto, et al. 2016)

Penyebaran jenis-jenis burung sangat dipengaruhi oleh habitat tempat hidup burung, meliputi adaptasi burung terhadap lingkungan, kompetisi, strata vegetasi, ketersediaan pakan dan seleksi alam seperti ditemukan didaerah hutan, laut, perkotaan, dan perdesaan. Beberapa kawasan hutan lebih banyak dijumpai berbagai jenis burung diantaranya di hutan dataran tinggi seperti hutan gunung (Partasasmita, et al. 2009; Hadiprayitno, et al, 2016). Dalam ekosistem, aves merupakan hewan yang memiliki peran yang menguntungkan seperti sebagai penyebar biji dan penyerbuk alami bagi tumbuhan yang sangat membantu petani dalam budidaya tanaman pangan. Selain itu juga sebagai pemangsa dan mempercepat pelapukan kayu-kayu busuk (Mackinnon, J. 2010). Ketersediaan lahan vertikal dan tutupan hutan tropis merupakan habitat bagi sebagian besar spesies burung (Partasasmita, et al. 2017; Kupsch, et al. 2019). Maka dari itu, diperlukan perlindungan jumlah aves dalam ekosistem untuk 
menjaga kelestariannya. Burung sebagai salah satu komponen ekosistem memiliki hubungan timbal balik dan saling ketergantungan dengan lingkungannya yang tidak terganggu (Anggriana, et al. 2018; Kartikasari, et al. 2018).

Kegiatan konservasi burung selama ini masih cenderung dilakukan di daerah yang dilindungi, hutan primer, hutan yang belum terganggu, atau ditekankan pada jenis yang terancam punah, sejauh ini sangat sedikit perhatian yang diberikan kepada jenis-jenis yang umum dijumpai atau pun jenis yang mendiami hutan sekunder. Perubahan terhadap spesies burung, morfologi, fisiologi, dan komposisi komunitas burung sehingga keletarian dan fungsi hutan perlu diperhatikan karena keberadaan burung di suatu daerah menjadi indikator perubahan lingkungan (Ayat, 2011; Nurmaeti, et al. 2018). Perubahan lahan global mengakibatkan penurunan drastic bagi keanekaragaman hayati sehingga hilanggnya fungsi ekologi, keanekaragaman dan kelimpahan burung tergantung pada jumlah pohon (Teuscher, et al. 2015). Hutan merupakan ekosistem terestrial yang luas dan yang banyak ditumbuhi oleh pohopohon berbuah yang menyediakan makanan bagi burung yang tumbuh secara alami maupun hasil penanaman manusia, ketersediaan makanan yang berlimpah dapat dijadikan kawasan konservasi (Mulyadi, 2010; Nugroho, et al. 2015). Sebagian besar kawasan hutan Indonesia merupakan hutan yang memiliki curah hujan tinggi. Pengelolaan kawasan hutan pegunungan di Jawa Barat diperlukan langkah bijak pemerintah untuk mencegah perambahan dan alih fungsi hutan menjadi lahan produksi oleh masyarakat, apabila tidak ingin kehilangan fungsinya. (Widodo, 2015; Mulyani, et al. 2013).

Cagar Alam merupakan salah satu kawasan konservasi yang memiliki peran sebagai tempat perlindungan berbagai spesies dan sebagai salahsatu upaya konservasi keragaman hayati. Fakta menunjukkan bahwa banyak permasalahan yang dihadapi dalam pengelolaan kawasan konservasi di Indonesia, diantaranya pengelolaan kawasan yang belum optimal dan kebutuhan lahan untuk pemekaran wilayah. Berdasarkan administratif pemerintahan, kawasan Cagar Alam Pananjung terletak di Desa Pangandaran, Kecamatan Pangandaran, Kabupaten Pangandaran, Propinsi Jawa Barat, sedangkan secara geografis kawasan TWA Pananjung Pangandaran terletak pada koordinat 108 $39^{\prime} 18^{\prime \prime}-108^{\circ} 39^{\prime} 52^{\prime \prime}$ BT dan $7^{\circ} 42^{\prime} 16^{\prime \prime}-7^{\circ} 42^{\prime} 35^{\prime \prime}$ LS. Keadaan topografi kawasan CA/TWA Pananjung Pangandaran pada umumnya landai hingga berbukit kecil dengan ketinggian antara 0-20 mdpl. Keadaan berbukit di temukan dibagian selatan CA/TWA Pangandaran, memanjang di sepanjang perbatasan wilayah tersebut mulai dari Ciborok (Barat) sampai Cirengganis (Timur), keadaan bukit tersebut dalam bentuk tonjolan-tonjolan batu karang terjal dan terpisah-pisah. KawasanCA/TWA Pananjung Pangandaran mempunyai curah hujan rata-rata $3.196 \mathrm{~mm} /$ tahun dengan suhu berkisar 25$30^{\circ} \mathrm{C}$ dan kelembaban udara antara $80-90 \%$. Musim basah atau hujan terjadi pada Oktober -Maret bersamaan dengan bertiupnya angin barat/barat laut, sedangkan musim kering terjadi pada bulan Juli -September selama periode musim angin tenggara (BBKSDA Jabar, 2016).

Jawa barat merupakan salah satu provinsi di Indonesia yang memiliki tingkat keanekaragam kelas aves yang cukup tinggi. Jawa barat memiliki 467 spesies burung 63 diantaranya termasuk burung endemik (HBW and BirdLife International, 2018). Beberapa jenis burung termasuk dalam jenis burung yang langka dan dilindungi sehingga diperlukan perhatian khusus agar spesies tersebut berkembangbiak secara optimal agar terhindar dari kepunahan, menyelamatkan spesies dari kepunahan adalah prinsip sentral dari konservasi (Hasibuan, et al, 2018; Jepson, 2016). Perburuan dan perdagangan, hilangnya habitat dan perubahan iklim dapat mengancam migrasi burung sehingga menjadi kendala untuk konservasi (Yong, et al. 2015; Burner, et al. 2018). Beberapa spesies burung banyak diperjual-belikan, hal ini dapat meningkatkan perburuan. Tidak menutup kemungkinan spesies burung yang dilindungi dan status terancam diburu untuk keperluan ekonomi. Untuk itu perlu adanya dilakukan identifikasi pada spesies burung di setiap daerah. Kegiatan konservasi dapat dilakukan melalui program pengembangan birding, sehingga dapat dijadikan potensi untuk pengembangan ekowisata (Muttaqien, et al. 2015). Penelitian ini bertujuan untuk mengidentifikasi keanekaragaman kelas aves yang terdapat di kawasan Cagar Alam Pananjung Pangandaran Jawa Barat dalam upaya mendata jenis burung yang tersebar diwilayah tersebut untuk tujuan membuat database burung di Jawa Barat dan sebagai upaya konservasi dimasa yang datang. 


\section{METODE/EKSPERIMEN}

Metode penelitian yang digunakan dalam penelitian ini adalah metode deskriptif dengan cara observasi langsung ke lokasi penelitian. Metode deskriptif merupakan suatu metode yang mendeskripsikan atau menggambarkan fenomena-fenomena yang ada dengan melakukan observasi langsung ke lokasi penelitian (Sukmadinata, 2016). Metode ini digunakan untuk mendeskripsikan spesies burung hasil pengamatan pada setiap stasiun. Desain penelitian menggunakan Point count (Gambar 1). Point count memungkinkan seorang pengamat berdiri diam di satu lokasi tertentu (sebuah stasiun sensus) merekamsemua burung terlihat dan terdengar selama periode hitungan tetap. Dengan point countseorang pengamat memiliki kesempatan yang lebih baik (Bibby, et al., 2000).

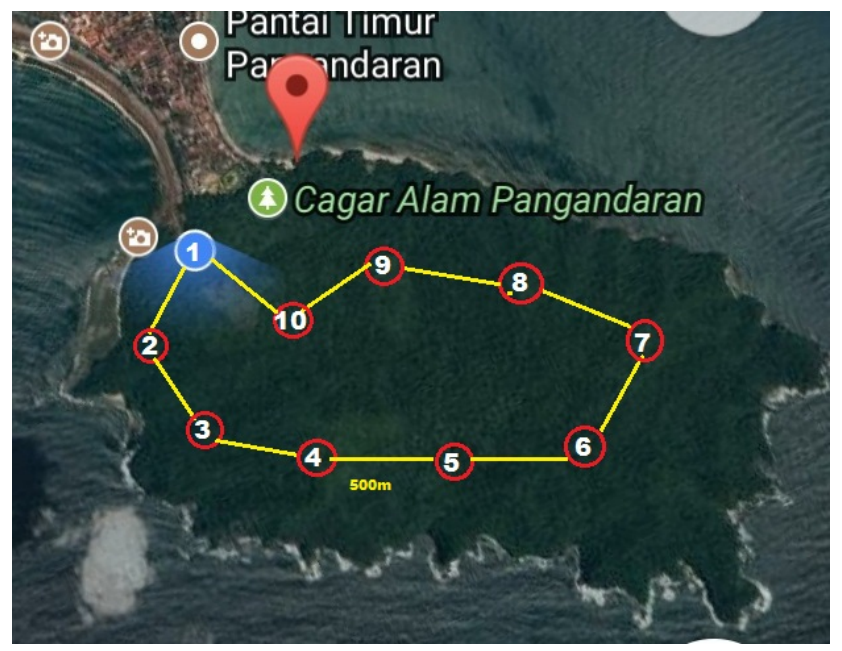

Gambar 1. Desain Point Count pengamatan aves di kawasan Cagar Alam Pananjung Pangandaran

Penelitian ini dilaksanakan selama tiga hari dari tanggal 7-9 Agustus 2018 di Kawasan Cagar Alam Pananjung Kabupaten Pangandaran. Pengamatan dilakukan mulai pukul 07.00-17.00. Terdapat Sepuluh titik (10 stasiun) pengamatan, setiap titik pengamatan berjarak 500 meter, durasi waktu pada setiap titik pengamatan selama 20 menit. Pengamatan dilakukan pengulangan sebanyak 3 kali. Populasi penelitian meliputi semua burung yang terdapat di kawasan Cagar Alam. Sampel penelitian diambil yaitu jenis burung yang tercuplik selama pengamatan. Pada penelitian ini tidak ideskripsikan jumlah dari masing-masing jenis burung, penelitian ini hanya unruk mengidentifikasi jenis-jenis burung yang terdapat di di kawasan Cagar Alam Pananjung.

\section{HASIL DAN PEMBAHASAN}

Hasil

Berdasarkan hasil pengamatan selama 3 kali pengulangan ditemukan 43 jenis burung yang terdapat di Kawasan Cagar Alam Pananjung. Kami menemukan sebanyak 26 famili selama pengamatan (Tabel 1). Kawasan Cagar Alam panajung di dominasi oleh family Pycnonotidae. Famili Pycnonotidae banyak ditemukan karena burung dari famili ini memiliki kebiasaan tinggal pada hutan sekunder, maupun daerah pinggiran hutan (MacKinnon, et al. 2010). 
Tabel 1. Daftar Burung Hasil Pengamatan di Kawasan Cagar Alam Pananjung Pangandaran

\begin{tabular}{|c|c|c|c|c|}
\hline No & Famili & Nama Daerah & Nama IImiah & Status \\
\hline 1 & Pycnonotidae & $\begin{array}{l}\text { Cucak kuning } \\
\text { Cucak kutilang } \\
\text { Merbah belukar } \\
\text { Merbah cerukcuk } \\
\text { Merbah corok-corok }\end{array}$ & $\begin{array}{l}\text { Pycnonotus flaviventris } \\
\text { Pycnonotus aurigaster } \\
\text { Pycnonotus plumosus } \\
\text { Pycnonotus goiavier } \\
\text { Pycnonotus simplex }\end{array}$ & \\
\hline 2 & Alcedinidae & $\begin{array}{l}\text { Cekakak jawa } \\
\text { Cekakak sungai } \\
\text { Raja udang meninting }\end{array}$ & $\begin{array}{l}\text { Halcyon cyanoventris } \\
\text { Todirhamphus chloris } \\
\text { Alcedo meninting }\end{array}$ & Endemik \\
\hline 3 & Capitonidae & $\begin{array}{l}\text { Takur tenggeret } \\
\text { Takur tulung-tumpuk }\end{array}$ & $\begin{array}{l}\text { Megalaima australis } \\
\text { Megalaima javensis }\end{array}$ & $\begin{array}{l}\text { Endemik/terancam } \\
\text { punah }\end{array}$ \\
\hline 4 & Cisticolidae & $\begin{array}{l}\text { Perenjak coklat } \\
\text { Perenjak jawa }\end{array}$ & $\begin{array}{l}\text { Prinia polychroa } \\
\text { Prinia familiaris }\end{array}$ & \\
\hline 5 & Muscicapidae & $\begin{array}{l}\text { Kucica hutan } \\
\text { Sikatan bubik }\end{array}$ & $\begin{array}{l}\text { Copsychus malabaricus } \\
\text { Muscicapa latirostris }\end{array}$ & \\
\hline 6 & Sittidae & $\begin{array}{l}\text { Munguk beledu } \\
\text { Munguk loreng }\end{array}$ & $\begin{array}{l}\text { Sitta frontalis } \\
\text { Sitta azurea }\end{array}$ & \\
\hline 7 & Estrildidae & $\begin{array}{l}\text { Bondol peking } \\
\text { Burung gereja erasia }\end{array}$ & $\begin{array}{l}\text { Lonchura punctulata } \\
\text { Passer montanus }\end{array}$ & \\
\hline 8 & Phasianidae & $\begin{array}{l}\text { Ayam hutan hijau } \\
\text { Ayam-hutan merah } \\
\text { Merak hijau }\end{array}$ & $\begin{array}{l}\text { Gallus varius } \\
\text { Gallus gallus } \\
\text { Pavo muticus }\end{array}$ & $\begin{array}{l}\text { Endemik } \\
\text { Endemik/rentan }\end{array}$ \\
\hline 9 & Apodidae & $\begin{array}{l}\text { Walet sapi } \\
\text { Kapinis Laut } \\
\text { Walet Gunung }\end{array}$ & $\begin{array}{l}\text { Collocalia esculenta } \\
\text { Apus pasificus } \\
\text { Aerodramus Vulcanorum }\end{array}$ & \\
\hline 10 & Falconidae & Elang alap sapi & Falco moluccensis & Endemik \\
\hline 11 & Ardeidae & $\begin{array}{l}\text { Kuntul karang } \\
\text { Kuntul Kecil }\end{array}$ & $\begin{array}{l}\text { Egretta sacra } \\
\text { Egretta garzetta }\end{array}$ & \\
\hline 12 & Bucerotidae & Kangkareng perut-putih & Anthracoceros albirostris & \\
\hline 13 & Columbidae & $\begin{array}{l}\text { Walik kembang } \\
\text { Pergam Katanjar }\end{array}$ & $\begin{array}{l}\text { Ptilinopus melanospilus } \\
\text { Ducula rosacea }\end{array}$ & $\begin{array}{l}\text { Endemik/terancam } \\
\text { punah }\end{array}$ \\
\hline & & Dederuk Jawa & Streptopelia bitorquata & \\
\hline 14 & Picidae & Caladi tilik & Dendrocopos moluccensis & \\
\hline 15 & Corvidae & Gagak hutan & Corvus enca & \\
\hline 16 & Accipitridae & Elang-laut perut putih & Haliaeetus leucogaster & \\
\hline 17 & Cuculidae & Kadalan birah & Phaenicophaeus curvirostris & \\
\hline 18 & Strigidae & Beluk ketupa & Ketupa ketupu & \\
\hline 19 & Aegithinidae & Cipoh kacat & Aegithina tiphia & \\
\hline 20 & Dicaeidae & Cabai jawa & Dicaeum trochileum & Endemik \\
\hline 21 & Sylviidae & Cinenen jawa & Orthotomus sepium & \\
\hline 22 & Nectariniidae & Burung madu kelapa & Anthreptes malacensis & \\
\hline 23 & Artamidae & Kekep babi & Artamus leucorynchus & \\
\hline 24 & Laridae & Dara laut sayap putih & Chlidonias leucopterus & \\
\hline 25 & Laniidae & Bentet loreng & Lanius tigrinus & \\
\hline 26 & Campephagidae & Jingjing batu & Hemipus hirundinaceus & \\
\hline
\end{tabular}

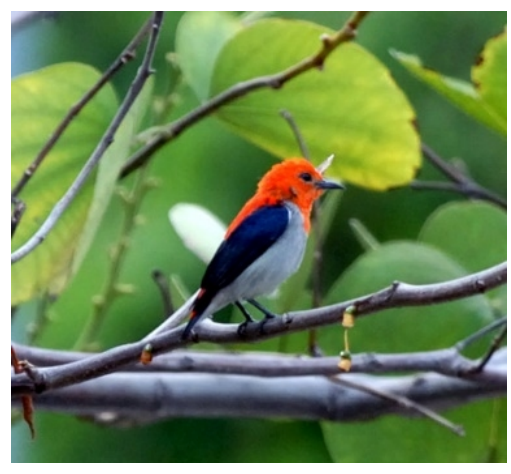

Gambar 2. Cabai Jawa salah satu Burung endemik Jawa Barat.
Pada setiap stasiun pengamatan dilakukan identifikasi dengan cara mencatat pada setiap burung yang tercuplik. Kondisi lingkungan berpengaruh pada benyaknya jenis burung yang teramati. Kami tidka menghitung jumlah spesies yang tercuplik pada setiap stasiun, namun dalam penelitian ini kami hanya menghitung jenis spesies yang tercuplik. Dari hasil pengamatan kami menemukan 7 (tujuh) spesies burung yang termasuk endemik yaitu: Cekakak Jawa (Halcyon cyanoventris), Ayam Hutan Hijau (Gallus Varius), Merak Hijau (Pavo muticus), Elang Alap Sapi (Falco moluccensis), Pergam Katanjar (Ducula rosacea), Takur Tulung-tumpuk (Megalaima javensis) dan Cabai Jawa (Dicaeum trochileum) (Gambar 2). Diantara spesies 
endemic terdapat spesies yang terancam punah yaitu takur Tulung-tumpuk dan Pergam Katanjar. Dan satu spesies yang termasuk dalam kategori rentan yaitu Merak Hijau.

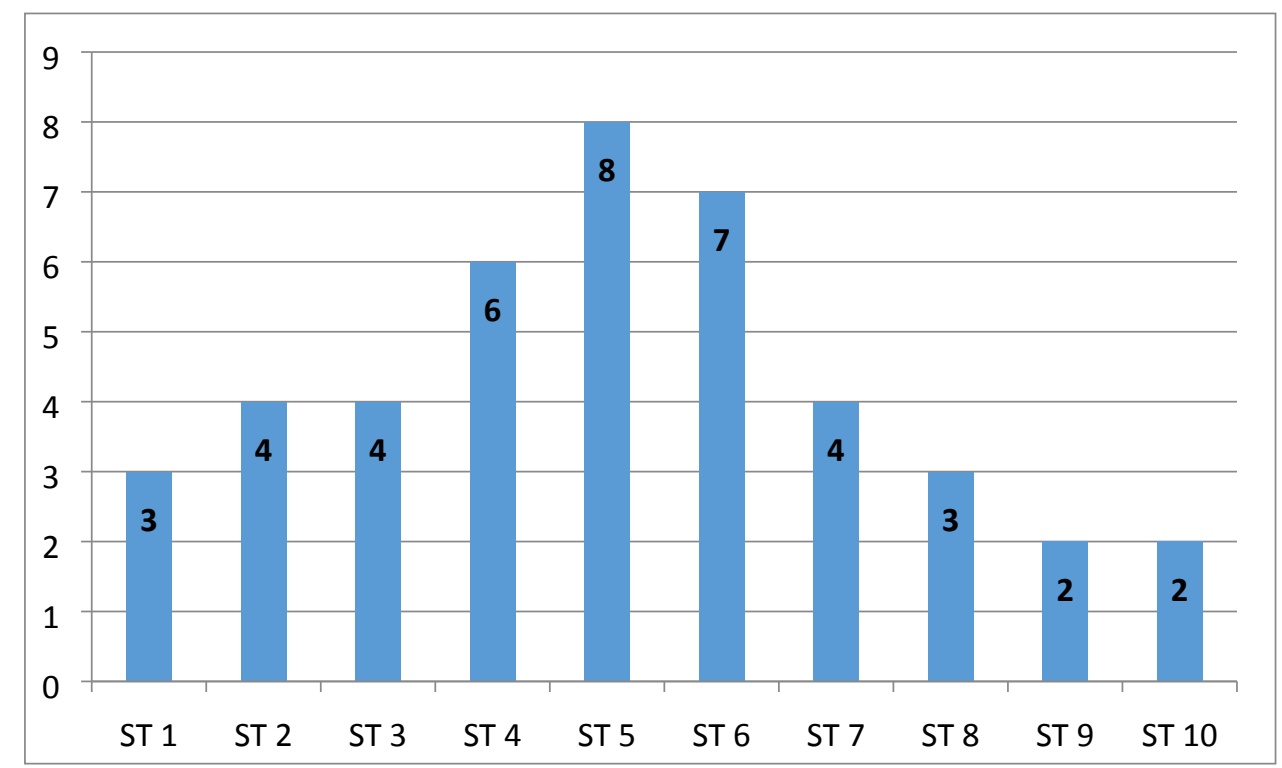

Gambar 3. Data jumlah jenis burung yang teramati pada setiap stasion

\section{Pembahasan}

Kondisi lingkungan sangat berpengaruh pada habitat jenis burung. Keanekaragaman jenis burung di Indonesia sering kali dikaitkan dengan kondisi lingkungan, semakin tinggi keanekaragaman jenis burung maka semakin seimbang suatu ekosistem di wilayah tempat hidup burung (Endah \& Partasasmita, 2015). Pada stasiun 1 (ST 1) ditemukan 3 jenis burung hal ini dikarenakan lokasi pengamatan dekat dengan taman wisata yang banyak pengunjung. Begitu pula pada stasiun 9 (ST 9) dan stasiun 10 (ST 10). Jenis burung hasil pengamatan tertinggi terdapat pada stasiun 5 (ST 5) sebanyak 8 jenis burung. Begitupun pada stasiun $4(n=6)$ dan stasiun $6(n=7)(G a m b a r 3)$. Berdasarkan hasil anailisis data dapat dijadikan indikator untuk status konservasi sehingga dapat menunjukkan tingkat keterancaman spesies dari kepunahan. Status konservasi ini ditetapkan dengan tujuan untuk memberikan perlindungan dan pelestarian terhadap spesies. Berdasarkan hasil pengamatan terdapat satu jenis yang termasuk dalam status Near Threatened (mendekati terancam punah) yaitu burung Takur Tulung-tumpuk (Megalaima javensis) dan Pergam Katanjar (Ducula rosacea), satu jenis termasuk dalam status Vulnerable (rentan) yaitu Merak Hijau (Pavo muticus). Turunnya populasi burung Merak Hijau disebabkan oleh pemburuan karena memiliki nilai komersil yang tinggi (Takandjandji dan Sawitri, 2011). penurunan populasi burung secara tidak langsung mempengaruhi keseimbangan ekologi dan konservasi, sehingga diperlukan pelestarian (Kurniawan, et al, 2017). Perburuan dan perdagangan, hilangnya habitat dan perubahan iklim dapat mengancam migrasi burung sehingga menjadi kendala untuk konservasi (Yong, et al. 2015; Burner, et al. 2018). Perlu tindak lanjut dari pemerintah setempat untuk membuat peraturan yang tegas untuk menyelamatkan beberapa spesies burung yang termasuk dalam kategori langka atau terancam punah.

Hutan merupakan tempat yang cocok bagi sebagian besar spesies khususnya burung untuk berkembang biak dan bertahan hidup. Beberapa kawasan hutan yang banyak dijumpai berbagai jenis burung diantaranya di hutan dataran tinggi seperti hutan gunung (Partasasmita, et al. 2009; Hadiprayitno, et al, 2016). Burung memiliki peran yang menguntungkan di hutan seperti sebagai penyebar biji dan penyerbuk alami bagi tumbuhan. Selain itu juga sebagai pemangsa dan mempercepat pelapukan kayu-kayu busuk (Mackinnon, J. 2010). Jenis burung digolongkan ke dalam kategori dilindungi berdasarkan beberapa faktor diantaranya: populasi sedikit, keterbatasan habitat alami sehingga tidak dapat berkembang biak, terjadi penurunan populasi yang signifikan akibat perburuan. 
Perubahan terhadap spesies burung, morfologi, fisiologi, dan komposisi komunitas burung sehingga keletarian dan fungsi hutan perlu diperhatikan karena keberadaan burung disuatu daerah menjadi indikator perubahan lingkungan (Ayat, 2011; Nurmaeti, et al. 2018).

Berdasarkan hasil pengamatan setiap stasiun jelas bahwa jenis burung lebih banyak ditemukan di kawasan hutan (stasiun 4, 5 dan 6). Pada stasiun tersebut didominasi oleh tumbuhan dengan pohonpohon yang tinggi. Perubahan lahan global mengakibatkan penurunan drastic bagi keanekaragaman hayati sehingga hilanggnya fungsi ekologi, keanekaragaman dan kelimpahan burung tergantung pada jumlah pohon (Teuscher, et al. 2015). Hutan merupakan ekosistem terestrial yang luas dan yang banyak ditumbuhi oleh poho-pohon berbuah yang menyediakan makanan bagi burung yang tumbuh secara alami maupun hasil penanaman manusia, ketersediaan makanan yang berlimpah dapat dijadikan kawasan konservasi (Mulyadi, 2010; Nugroho, et al. 2015). Sebagian besar kawasan hutan Indonesia merupakan hutan yang memiliki curah hujan tinggi. Pengelolaan kawasan hutan pegunungan di Jawa Barat diperlukan langkah bijak pemerintah untuk mencegah perambahan dan alih fungsi hutan menjadi lahan produksi oleh masyarakat, apabila tidak ingin kehilangan fungsinya. (Widodo, 2015; Mulyani, et al. 2013). Burung lebih menyukai hidup dan berkembang biak pada hutan yang memiliki pohon-pohon yang tinggi, karena mereka merasa aman terlepas dari gangguan terutama manusia. Sekarang saatnya kita sadar bahwa perburuan burung untuk keperluan komersil dapat mengancam populasi. Mungkin saja pada beberapa tahun yang akan datang beberapa jenis burung akan sulit kita temukan karena populasi yang menurun drastis bahkan punah.

\section{PENUTUP}

Hasil identifikasi aves di kawasan Cagar Alam Pananjung Pangandaran melalui pengamatan setiap stasiun ditemukan 43 jenis burung yang teramati dari 26 famili. Hasil pengamatan terdapat satu jenis yang termasuk dalam status Near Threatened (mendekati terancam punah) yaitu burung Takur Tulung-tumpuk (Megalaima javensis) dan Pergam Katanjar (Ducula rosacea), satu jenis termasuk dalam status Vulnerable (rentan) yaitu Merak Hijau (Pavo muticus). Analisis data setiap stasiun dapat disimpulkan bahwa sebagian besar burung banyak ditemukan dikawasan hutan dengan vegetasi pohon-pohon tinggi daripada didaerah wisata yang banyak pengunjung. Hasil dari penelitian ini dapat dijadikan sebagai tambahan data atau informasi untuk upaya konservasi dimasa yang akan datang.

\section{UCAPAN TERIMAKASIH}

Penelitian ini sepenuhnya didanai oleh BPPDN Dikti, kami mengucapkan terimakasi yang sebesar-besarnya atas dukungan yang sangat berharga dan pihak-pihak yang telah membantu terlaksananya penelitian ini.

\section{DAFTAR PUSTAKA}

Anggriana, P., Dewi, B. S., \& Winarno, G. D. (2018). Populasi dan Pola Sebaran Burung Kuntul Besar (Egretta alba) di Lampung Mangrove Center. Jurnal Sylva Lestari, 6(3), 73-80. https://doi.org/10.23960/jsl3673-80

Ayat, A., \& Tata, H. L. (2015). Diversity of birds across land use and habitat gradients in forests, rubber agroforests and rubber plantations of North Sumatra. Indonesian Journal of Forestry Research, 2(2), 103-120. https://doi.org/10.20886/ijfr.2015.2.2.103-120

Ayat, A. (2011). Panduan Lapangan Burung-Burung Agroforest di Sumatra (In: Mardiastuti A, eds. Bogor, Indonesia. World Agroforestry Centre - ICRAF, SEA Regional Office).

BBKSDA Jabar. (2016). Tentang Cagar Alam Pananjung Pangandaran. http://bbksdajabar.ksdae.menlhk.go.id/wp-content/uploads/2017/08/Profil-Bidwil-3-

Fix skw 6 pangandaran.pdf 
Bibby, C., Martin J., \& Stuart M. (2000). Teknik-teknik Ekspedisi Lapangan Survei Burung. BirdLife International-Indonesia Programme, Bogor.

Burner, R. C., Shakya, S. B., Haryoko, T., Irham, M., Prawiradilaga, D. M., \& Sheldon, F. H. (2018). Ornithological observations from Maratua and Bawean Islands, Indonesia. TREUBIA, 45, 11 24. http://dx.doi.org/10.14203/treubia.v45i0.3445

Endah, G. P., \& Partasasmita, R. (2015). Keanekaan jenis burung di Taman Kota Bandung, Jawa Barat. Pros Sem Nas Masy Biodiv Indon, 1, 1289-1294. https://doi.org/10.13057/psnmbi/m010605

Hadiprayitno, G., Mertha, I. G., \& Ilhamdi, M. L. (2016). Species richness and birds conservation priority in Mount Rinjani Areas, Lombok. Biosaintifika: Journal of Biology \& Biology Education, 8(3), 270-277. https://doi.org/10.15294/biosaintifika.v8i3.5039

HBW and BirdLife International. (2018). Handbook of the Birds of the World and BirdLife International digital checklist of the birds of the world. Version 3. Available at: https://avibase.bsceoc.org/checklist.jsp?lang=EN\&p2=1\&list=birdlife\&synlang=\&region=IDjaba\&version=text\&life list=\&highlight=0.\&lang=EN\&p2=1\&list=birdlife\&synlang=\&region=IDjaba\&version=text\&lifelist $=$ \&highlight $=0$

Jepson, P. R. (2016). Saving a species threatened by trade: a network study of Bali starling Leucopsar rothschildi conservation. Oryx, 50(3), 480-488. https://doi.org/10.1017/S0030605314001148

Kartikasari, D., Pudyatmoko, S., Wawandono, N. B., \& Utami, P. (2018). Komposisi Guild Komunitas Burung di Area Panas Bumi Cagar Alam dan Taman Wisata Alamkamojang Jawa Barat Indonesia. Jurnal Hutan Tropis, 6(2), 124-136. https://doi.org/10.20527/jht.v6i2.5400

Kupsch, D., Vendras, E., Ocampo-Ariza, C., Batáry, P., Motombi, F. N., Bobo, K. S., \& Waltert, M. (2019). High critical forest habitat thresholds of native bird communities in Afrotropical agroforestry landscapes. Biological Conservation, 230, 28. https://doi.org/10.1016/j.biocon.2018.12.001

Kurniawan, I. S., Tapilow, F. S., \& Hidayat, T. (2017, September). How can Smartphone-Based Internet Data Support Animal Ecology Fieldtrip?. In Journal of Physics: Conference Series (Vol. 895, No. 1, p. 012134). IOP Publishing. https://doi.org/10.1088/1742-6596/895/1/012134

MacKinnon, J., Karen, P. \& Balen, B. (2010). Seri Panduan Lapangan Burung- Burung Di Sumatera, Jawa, Bali, dan Kalimantan. Puslitbang Biologi- LIPI, Bogor

Mulyadi, A. (2010). Pengetahuan Lingkungan Hidup. Bandung: Prisma Press.

Mulyani, Y. A., Ulfah, M. \& Sutopo. (2013). Bird Use of Several in An Academic Campus of Institut Pertanian Bogor in Darmaga, Bogor, West Java. Media Konservasi, 18(1), 18-27.

Muttaqien, H. Z., Hakim, L., \& Leksono, A. S. (2015). Analysis of bird diversity for supporting ecotourism development in Rajegwesi, Meru Betiri National Park. Journal of Indonesian Tourism and Development Studies, 3(3), 105-110. https://doi.org/10.21776/ub.jitode.2015.003.03.03

Nugroho, A. S., Anis, T., \& Ulfah, M. (2015, June). Analisis Keanekaragaman Jenis Tumbuhan Berbuah di Hutan Lindung Surokonto, Kendal, Jawa Tengah dan Potensinya Sebagai Kawasan 
Konservasi Burung. In Pros Seminar Nasional Masyarakat Biodiversitas Indonesia (Vol. 1, No. 3, pp. 472-476). https://doi.org/10.13057/psnmbi/m010316

Nurmaeti, C., Abidin, Z., \& Prianto, A. (2018). Keanekaragaman Burung pada Zona Penyangga Taman Nasional Gunung Ciremai. Quagga: Jurnal Pendidikan dan Biologi, 10(2), 54-59.

Partasasmita, R., Atsaury, Z. I. A,. \& Husodo, T. (2017). The use of forest canopy by various bird species in tropical forest montana zone, the Nature Reserve of Mount Tilu, West Java, Indonesia. Biodiversitas, 18(2), 453-457. https://doi.org/10.13057/biodiv/d180202

Partasasmita, R., Mardiastuti, A., Solihin D. D., Widjajakusuma, R., Prijono, S. N. \& Ueda, K. (2009). Komunitas Burung Pemakan Buah di Habitat Suksesi. Jurnal Biosfera, 26 (2): 90-99.

Riefani, M. K., Soendjoto, M. A., \& Munir, A. M. (2019). Bird species in the cement factory complex of Tarjun, South Kalimantan, Indonesia. Biodiversitas, 20(1), 218-225. http://eprints.ulm.ac.id/id/eprint/4904

Saefullah, A., Mustari, A. H., \& Mardiastuti, A. (2015). Keanekaragaman Jenis burung pada Berbagai Tipe Habitat Beserta Gangguannya di Hutan Penelitian Darmaga, Bogor, Jawa Barat. Media Konservasi. 20(2): 117-124.

Sukmadinata, N. (2016). Metode Penelitian Pendidikan. Bandung: Remaja Rosdakarya.

Susanto, E., Mulyani, Y. A., \& Suryobroto, B. (2016). Bird Communities In Seblat Nature Recreation Park (SNRP) North Bengkulu, Bengkulu. Biosaintifika: Journal of Biology \& Biology Education, 8(1), 25-32. https://doi.org/10.15294/biosaintifika.v8i1.4948

Takandjandji, M., \& Sawitri, R. (2011). Populasi Burung Merak Hijau (Pavo muticus Linnaeus, 1766) di Ekosistem Savana, Taman Nasional Baluran, Jawa Timur. Jurnal Penelitian Hutan dan Konservasi Alam, 8(1), 13-24.

Teuscher, M., Vorlaufer, M., Wollni, M., Brose, U., Mulyani, Y., \& Clough, Y. (2015). Trade-offs between bird diversity and abundance, yields and revenue in smallholder oil palm plantations in Sumatra, Indonesia. Biological Conservation, 186, 306-318. https://doi.org/10.1016/j.biocon.2015.03.022

Widodo, W. (2015). Kajian Kualitatif Kemelimpahan Spesies Burung di Hutan Pegunungan Telaga Bodas, Garut, Jawa Barat. Biosaintifika: Journal of Biology \& Biology Education, 7(1), 37-47. https://journal.unnes.ac.id/nju/index.php/biosaintifika/article/view/3533

Yong, D. L., Liu, Y., Low, B. W., Espanola, C. P., Choi, C. Y., \& Kawakami, K. (2015). Migratory songbirds in the East Asian-Australasian Flyway: a review from a conservation $\begin{array}{lll}\text { perspective. Bird } \quad \text { Conservation } & \text { 1-37. }\end{array}$ https://doi.org/10.1017/S0959270914000276 